\title{
Progress in Clear-Air Turbulence Research and Forecasting
}

\author{
By \\ Elmar R. Reiter
}

Technical Paper No. 54

Department of Atmospheric Science

Colorado State University

Fort Collins, Colorado

AIAA Paper No. 64-311

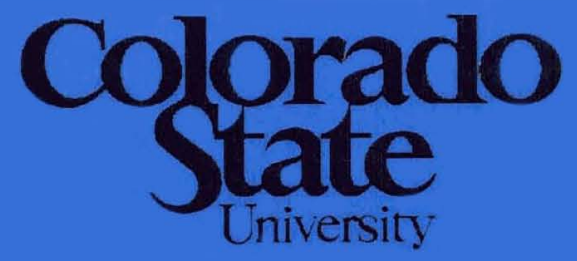

\section{Department of Atmospheric Science}

\author{
Paper No. 54
}




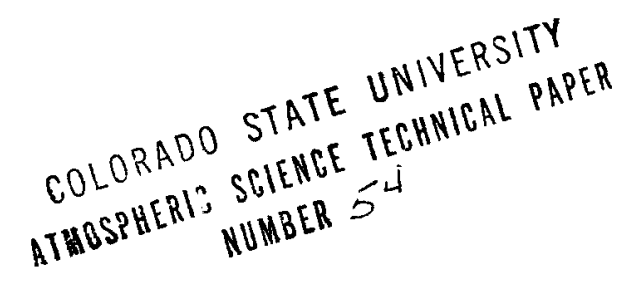

PROGRESS IN CLEAR-AIR TURBULENCE RESEARCH AND FORECASTING

by

ELMAR R. REITER

Colorado State University

Fort Collins, Colorado

AIAA Paper

No. 64-311

Washington, D. C. June 29 - July 2,1964 
Progress in Clear-Air Turbulence Research and Forecasting

by

EImar R. Reiter

\section{ABSTRACT}

A brlef description and summary of preliminary findings of Project TOPCAT will be given. This project consisted of clear-air turbulence (CAT) measurement flights executed by a specially instrumented Canberra aircraft over Southeast and Central Australia. The research program was initiated in order to augment our knowledge on the detailed structure of the upper troposphere and lower stratosphere in view of the requirements for supersonic transport operations.

Since during this project the task was to find rather than to avoid CAT, standard methods of forecasting this phenomenon were put to a critical test. Their inadequacy and possible ways of improvement will be outlined in this paper.

\section{Project TOPCAT Research Flights}

During the period July 21 to October 3 , 1963, 41 research flights were carried out over southeastern Australia by an instrumented Canberra aircraft of the Royal Aircraft Establishment, (R.A.E.), Farnborough, England. The purpose of these flight operations was to obtain detailed spectrum distributions of atmospheric gusts causing the phenomenon of clearair turbulence (CAT) in the upper troposphere and the lower stratosphere. The gust recordings obtained from these measurement flights are still being evaluated at the RAE and at the Aeronautical Research Laboratories of the Australian Department of Supply. Results should be forthcoming.

In support of these research flights, CAT forecasts had to be made under the consideration, that the aircraft should be dispatched into regions of expected turbulence in order to obtain gust records. As it turned out, this ob- jective provided a possibility of stringently testing present CAT forecasting methods, and of implementing new forecasting procedures where required.

\section{Present Status of CAT Information}

From past experience it has become a well established fact, that CAT is not necessarily tied to superadiabatic conditions and convective vertical motions as they may exist in parts of the troposphere. CAT is frequently encountered at and above tropopause level (Fig. 1) and within the "jet-stream front", a stable and baroclinic zone underneath the jet core (Fig. 2).

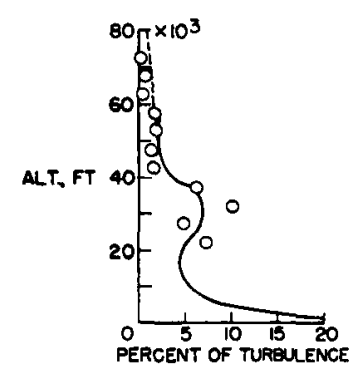

Fig. 1: Turbulence occurrence from U-2 data (circles, Coleman and Steiner 1960), and from data presented by Press and Steiner (1958) (solid line), and by Coleman and Stickle (1961) (dashed 1ine). (Rhyne and Steiner, 1962). 


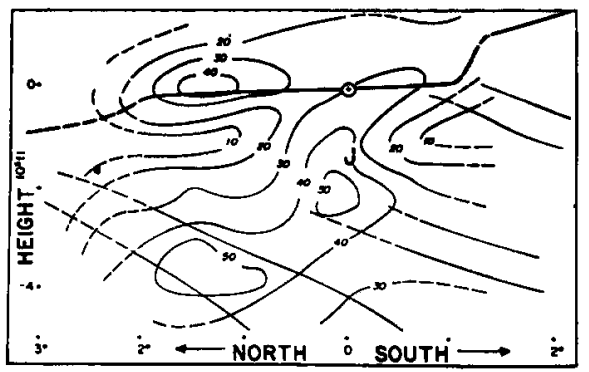
time (CAT) in per cent of total flying time for nine Project Jet Stream flights 1956-1957. T $=$ position of jet core. Horizontal distance from jet core in degrees of latitude, vertical distance in $10^{3}$ feet. Heavy line indicates tropopause. Stable layers are marked by sloping solid and dashed lines. (Sasaki 1958)

From close correlations between orographic features such as ranges of mountains or hills, coastlines, etc., with CAT occurrence in the upper troposphere and lower stratosphere (Clodman et. al. 1961) one was able to conclude that gravity-type wave disturbances are one of the causes leading to CAT in a stable environment (Reiter 1963a). Evidence of the existence of such wave disturbances of the required wave length (order of magnitude of $200 \mathrm{~m}$ for a conventional jet aircraft) could be gathered from photogrammetric studies of cirrus undulatus (Reiter, Hayman 1962; Reiter 1962, 1963 b, c ; Reiter, Nania 1964).

Theoretical studies (Helmholtz, 1888, 1889, 1890; Haurwitz 1941; Sekera 1948; Sasaki 1958; Panofsky and McLean 1964), may actually provide us with a physical "model" of CAT formation: Helmholtz waves below a certain critical wave length, or above a critical wave number forming along a temperature discontinuity with vertical wind shear, will amplify exponentially with time, thus leading to turbulence. This becomes evident from an instability criterion similar to Richardson's derived from the perturbation equations:

$$
R=\Delta \rho-\frac{K \bar{\rho}}{2 \mathrm{~g}}(\Delta V)^{2<}>0 \begin{aligned}
& \text { unstable } \\
& \text { stable }
\end{aligned}
$$

where $\Delta \rho$ is the density discontinuity across the interface, $\rho$ is the mean density $\Delta u$ is the vertical wind shear between the 2 layers under consideration, $K$ is the wave number, and $g$ the acceleration of gravity. The critical wave number, according to above expression would be

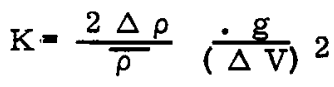

Richardson's original criterion

$$
\mathrm{Ri}=\frac{\mathrm{K}_{\mathrm{T}}}{\mathrm{K}_{\mathrm{M}}} \quad \frac{\mathrm{g}}{\theta} \quad \frac{\frac{\partial \theta}{\partial \mathrm{z}}}{\left(\frac{\delta \mathrm{V}}{\partial \mathrm{z}}\right)^{2}}
$$

formally - but not dimensionally - appears to be very similar to expression (2).

( $\mathrm{K}_{\mathrm{T}}$ is the exchange coefficient of heat, $\mathrm{K}_{\mathrm{M}}$ the exchange coefficient of momentum). The ratio. of these two coefficient has been assumed by Richardson to be 1 . According to Petterssen and Swinbank (1947) a value of 0.65 seems to be more likely.

Richardson's criterion has not given unambiguous correlations with CAT, mainly because critical values have been evaluated over too deep an atmospheric layer to be of significance for the meso-structural "sheets" in which CAT seems to occur.

This physical "model" of CAT may be extended to supersonic transport (SST) operations, considering the greater wave lengths of wave disturbances, to which this aircraft will respond. In addition to the input from alternating up and down drafts one should consider the effect of discontinuity surfaces in temperature which may be warped into a wave-like pattern. If a SST "skimmed" along such a discontinuity surface, a periodic change in Mach number may result in equivalent changes in the drag coefficient and consequently lead to CAT without a wind-generated cause (Reiter 1964a,b; Webb, 1963).

Statistical approaches in CAT research (Colson 1962, 1964) have tried to establish correlations between atmospheric flow parameters and patterns and the occurrence of turbulence. It has been found that combinations of jet streams and upper troughs, and regions of combined strong vertical and horizontal wind shears are prone to develop CAT (George, 1961). It has been mainly on the strength of statistical findings that routine forecasting techniques for CAT have been developed. 


\section{CAT Forecasting Techniques}

A method developed by George (1961) has been accepted widely for CAT forecasting. It is based on the assumption that a combination of strong horizontal ( $>50 \mathrm{kts} / 150$ nautical miles) and vertical wind shears ( $6 \mathrm{kts} / 1000 \mathrm{ft}$. is able to generate CAT. A wind speed of at least 60 knots should be present in the CAT region. This method usua1ly produces satisfactory forecasts near the "jet-stream front" of a well developed jet stream, where strong shears are concentrated within a stable and baroclinic layer. So, for instance, of the CAT cases shown in Fig. 3., the ones over the Alleghenies would have been predicted all right. As may be seen from the cross sections of Fig. 4,5 and 6 , turbulence is encountered in the stable region underneath the jet core. Scalar wind shears, both horizontal as well as vertical, are appreciable in this region, while the wind direction stays rather uniform throughout the upper troposphere.

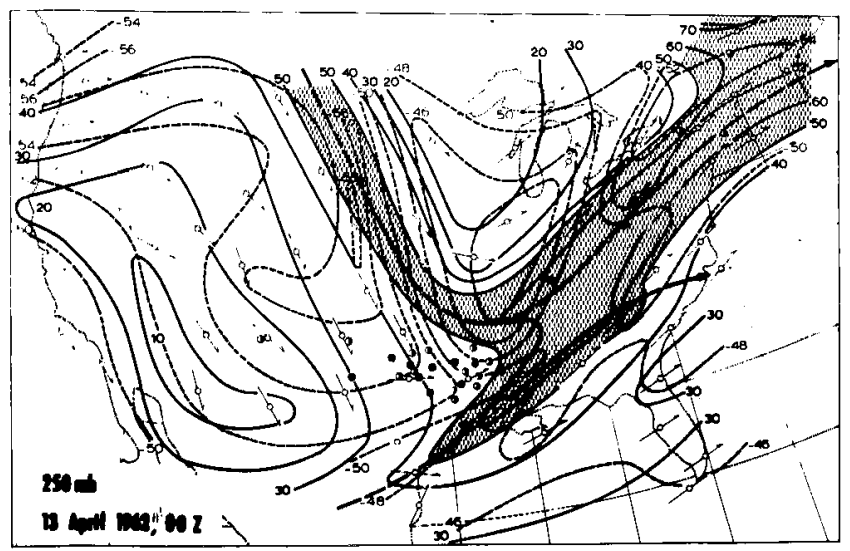

Fig. 3: Isotachs (solid lines, heavy numbers, mps) and isotherms (dashed Iines, light numbers, centigrade) of the 250-mb surface for 13 April 1962, 00 GCT. Regions with speeds $>50$ mps are shaded. Half-filled circles stand for reports of moderate CAT, heavy dots denote severe CAT. (Numerous reports of light CAT have been omitted). Wind directions at reporting station are indicated by arrows. Jet axes are shown by heavy dashed 1 ines and arrows.

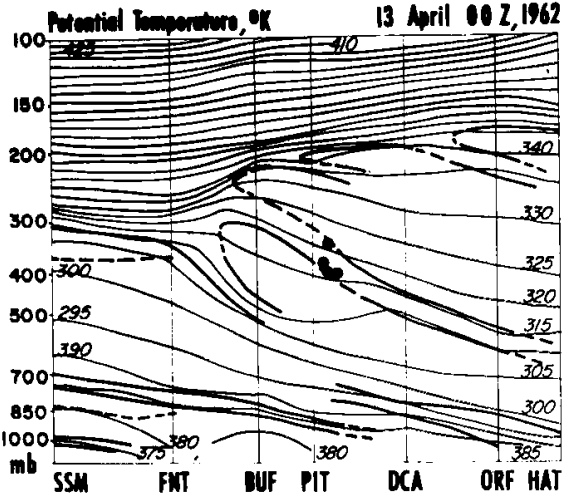

Fig. 4: Cross-section of potential temperature (degrees absolute) through the atmosphere from Sault Ste. Marie, Michigan (SSM), to Cape Hatteras, N. Carolina (HAT), 13 April 1962, 00 GCT. Stable layers and tropopause are marked by heavy lines. CAT in the vicinity of the cross-sectional plane: open inner circles -- light CAT; half-black inner circles -- moderate CAT; black inner circles -- severe CAT. The black portions of the outer rings indicate the time of CAT observation (plus or minus 6 hours from map time shown as black semi-circles to right or left of inner circle).

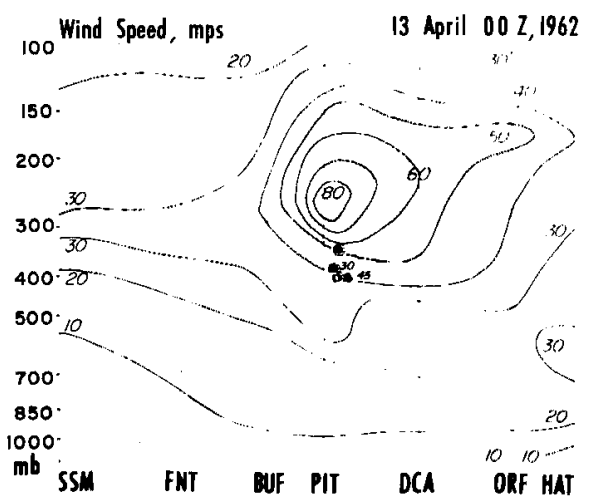

Fig. 5: Same as Fig. 4, except cross section of wind speeds (mps). Region with speeds $>60 \mathrm{mps}$ are shaded. 


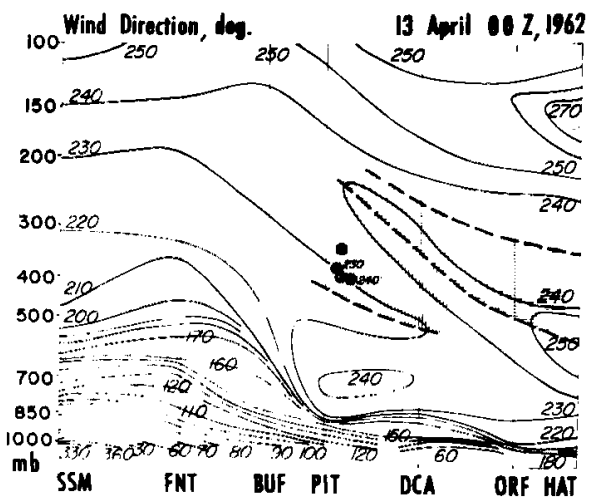

Fig. 6: Same as Fig. 4, except cross section of wind direction (degrees). Areas of backing and veering of wind with height in CAT region are indicated by different hatching.

There may be a slight disadvantage to this forecasting method as it is presently employed: It extends the air space for which CAT warnings a are issued, to $7000 \mathrm{ft}$. above and $3000 \mathrm{ft}$. below the layer in which critical shears are observed. Normally such deep air spaces cannot be avoided under the present Air Traffic Control (ATC) system.

\section{Forecasting Techniques Employed During Project TOPCAT}

During the first six weeks of Project TOPCAT, when CAT forecasts were made following established routines (Spillane 1964) it became evident that the CAT criteria employed were not stringent enough. Apparently there is a difference in the skill score for forecasts made in order to avoid rather than to search for CAT The two standards of measure could, of course, be combined into one, if CAT forecast but not encountered would be counted as failure, the same as CAT not predicted but encountered.

During the second half of the program, it was decided to place more emphasis on the mesostructure of the atmosphere in predicting CAT. The skill score improved accordingly by more than one order of magnitude (Reiter, 1964c).

The CAT forecasts were based upon the following considerations: Since horizontal wind shear hardly ever is of a magnitude to produce turbulence except for very special conditions (Clodman et.a1., 1961) it was abandoned as a forecasting tool. Shallow stable and baroclinic layers were searched for instead, since they are the primary reason for the existence of hori- zontal shears, and -- in combination with vertical shears -- would provide the physical setup for the formation of gravity waves. Such stable layers usually may be detected fairly easily from radiosonde records. Difficulties inherent in the rather sparse upper air network over Australia were in part overcome by careful analysis for time continuity. It should be mentioned at this point, that the smoothing of vertical temperature profiles, permissible under present coding regulations, obliterate's some of the shallow stable layers which may be of importance, especially in the upper troposphere near jet streams.

Vertical vector wind shear across these stable regions was taken as a second criterion. This vector shear could be produced either by a scalar increase of wind with height (see Fig. 5) or by a sharp turning of wind through a shallow layer. The latter situation was encountered several times over Australia during the second half of Project TOPCAT. It unfailingly produced CAT, even with winds only of the order of $30 \mathrm{kts}$. The criterion of a minimum speed of $60 \mathrm{kts}$, therefore, was abandoned for those cases where vertical shear was produced by turning of wind with height rather than by a linear increase without directional changes. A classical case of this kind over the United States, although with stronger winds, is presented in Figs. 7,8 , and 9 . The

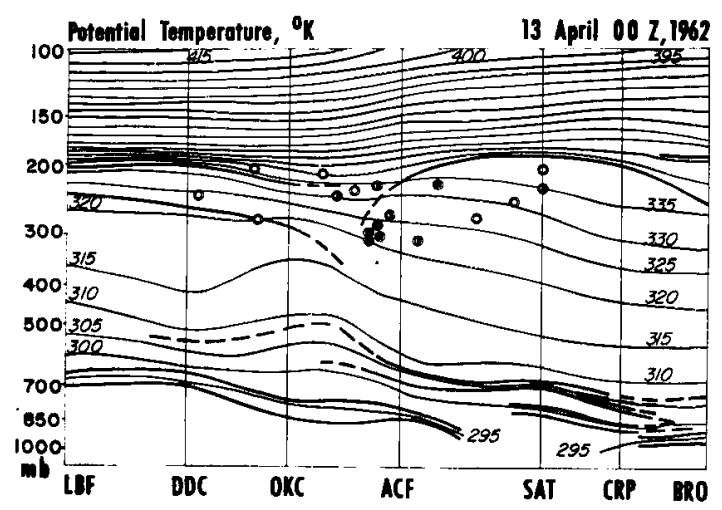

Fig. 7: Same as Fig. 4, except cross-sectional plane extending between North Platte, Nebraska (LBF), and Brownsville, Texas (BRO). 


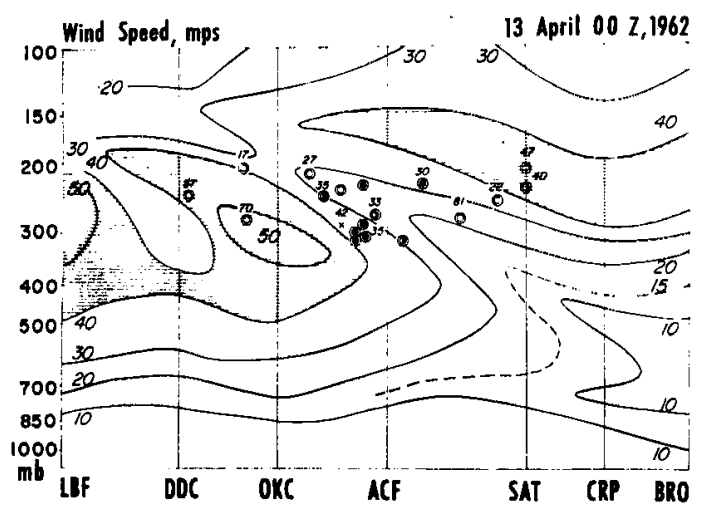

Fig. 8: Same as Fig. 7, except cross-section of wind speeds (mps). Regions with speeds $>40$ mps are shaded.

cases of CAT shown in these cross sections occur in the region of merging between two jet branches (Fig. 3). As may be inferted from this case study, the northern jet branch actually "dips" underneath the southern one. The rapid turning of wind with height, therefore, becomes an indicator of differential temperature advection (Schwerdtfeger and Radok, 1959). This, apparently, favors the formation of stable and baroclinic zones, which -- because of the existing vector wind shear -- may become subject to gravity-wave formation.

With the rather small number of research flights available, no accurate lower limits can be placed at this time on the vertical vectorwind shear required to produce CAT. It appears, however, the George's criterion for a scalar shear of $6 \mathrm{knots} / 1000 \mathrm{ft}$. may apply to vector shear as well.

\section{Suggestions for Future Research}

Our meteorological sounding system offers considerably more information than is presently used in routine analysis and forecasting operations. Since CAT seems to be a phenomenon associated with mesostructural details of vertical wind shear and temperature the vertical wind and temperature profiles measured by our sounding systems should be scanned for such details. This could easily be done by electronic computers.

Efforts should be made to establish a closer correlation between observed CAT occurrence and atmospheric layers rather than broad-scale features in flow patterns. Such correlations should

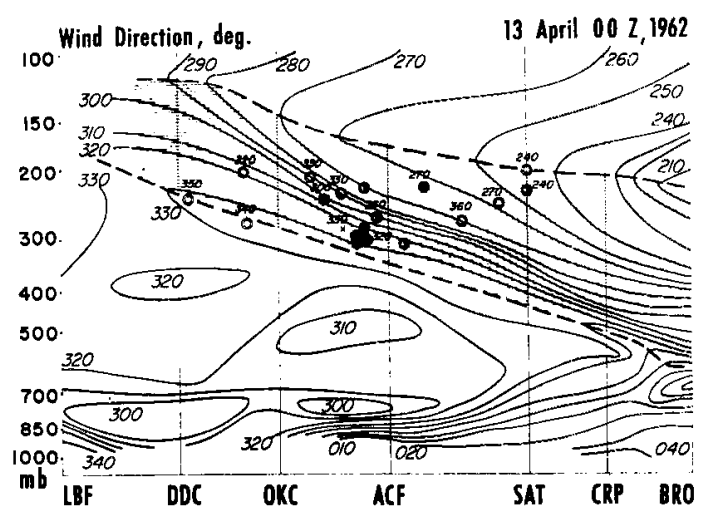

Fig. 9: Same as Fig. 7, except cross-section of wind direction (degrees). Areas of backing of wind with height in CAT region are indicated by shading.

help to overcome the difficulty of predicting CAT in too deep an air space and in too wide a region. With the employment of electronic computers it is hoped, that critical values of shear, stability and baroclinicity may be estab1 ished, and indices of CAT expectancy, perhaps simular to the ones proposed by Panofsky and McLean (1964) could be tested.

Measurement programs of CAT still have to be considered an important tool in exploring the physical nature of CAT. A preliminary study during Project TOPCAT, employing smoke trails in marking CAT regions, proved to be rather promising. In one particular instance, such a turbulent patch could be followed for 45 minutes while drifting downstream with the wind. So far, with only very few exceptions, CAT usually has been considered a by-product to atmospheric research flights. More knowledge on this phenomenon could be obtained at smaller cost if it were given a higher priority level in measurement programs. Especially the mesostructure of the stratosphere and its possible effect on SST operations are still in the stage of guesswork. Detailed measurements in this region should be of great interest to the aeronatutical engineering community as well as to meteorologists.

Last, but not least, a simple but effective in-flight CAT warning system is still lacking. Various techniques of ground-based radar detection of possible CAT - bearing layers may be technically feasible, but rather costly to put into operation. The possible effect of CAT on fastflying aircraft should provide enough challenge for research on detection devices. 


\section{REFERENCES}

Clodman, J., G.M. Morgan, Jr., and J.T. Ball 1961:

High level turbulence. Air Weather Service, Tech. Rep. 158.

Coleman, T.I., and $\dot{R}$. Steiner, 1960:

Atmospheric turbulence measurements obtained from airplane operations at altitudes between 20,000 and 75,000 feet for several areas in the Northern Hemisphere. NASA TN D-548.

Coleman, T.I., and J.W. Stickle, 1961:

Turbulence environment for supersonic transports. Paper presented at 5th Annual Symposium of the Society of Experimental Test Pilots, Beverly Hills, California, September 29-30, 1961.

Colson, DeVer, 1962:

Analysis of special clear-air turbulence program for March 1962. Paper given at 4th

Conference on Applied Meteorology, Hampton, Va., September 10-14, 1962.

Colson, DeVer, 1964:

Summary of high level turbulence program for 4-9 February, 1963. Paper given at 5th Conference on Applied Meteorology. Atlantic City, N.J., March 2-6, 1964.

George, J.J., 1961:

Prediction of clear-air turbulence. Shell Aviation News, No. 273.

Helmholtz, H.v., 1888, 1889:

Ueber atmosphaerische Bewegungen, I. und II., Sitzungsberichte d. Akademie der Wissenschaften, Berlin.

Helmholtz, H.v., 1890:

Die Energie der Wogen und des Windes. Sitzungsberichte d. Akademie der Wissensch., Berlin .

Panofsky, H., and J. McLean, 1964:

Physical mechanisms of clear-air turbulence. Department of Meteorol., Pennsylvania State Univ., Report.

Petterssen, S., and W.C. Swinbank, 1947:

On the application of the Richardson criterion to large-scale turbulence in the free atmosphere. Quart. J. Roy. Meteor. Soc. 73:335-345.

Press, H., and R. Steiner, 1958:

An approach to the problem of estimating severe and repeated gust 1oads for missile operations. NACA TN 4332.

Reiter, E.R., 1962:

The atmospheric micro-structure and its bearing on clear-air turbulence. Colorado State University, Atmosph. Sci. Tech. Paper No. 39.

Reiter, E.R., 1963a:

Jet Stream Meteorology. Univ. of Chicago Press, 515 pp.

Reiter, E.R., 1963b:

Die Feinstrucktur der Atmosphaere und ihre Messung. Beitr. Phys. d. Atmos. 36:157-172.

Reiter, E.R., 1963c:

Nature and observation of high-level turbulence especially in clear air. U.S. Navy Weather Research Facility. Norfolk, Va. NWRF 15-1262-071.

Reiter, E.R, , 1964a:

Jet streams and turbulence. To be published: Austral. Meteor. Magazine,

Reiter, E.R., 1964b:

CAT and SCAT. To be published: Aeronautics and Astronautics. 
Reiter, E.R., 1964c:

Forecasting of CAT for Project TOPCAT measurement flights, September 1-30, 1963. Report to be published: Department of Meteorol., University of Melbourne, Australia.

Reitér, E.R., and R.W, Hayman, 1962:

On the nature of clear-air turbulence (CAT). Colorado State University, Atmosph. Sci. Tech. Paper No. 28.

Retter, E.R, and A. Nania, 1964:

Jet-stream structure and clear-air turbulence (CAT). To be published: J. of Applied Meteorology.

Rhyne, R.H., and R. Steiner, 1962:

Turbulence and precipitation problems associated with operation of supersonic transports. Paper presented at Fourth Conference on Applied Meteorology, Hampton, Va., Sept. 10-14, 1962.

Sasaki, Y., 1958:

A theory and analysis of clear-air turbulence. Texas A \& M College. Dept. of Oceanogr. and Meteorol., Sci. Rep. No, 1, Contract No. AF 19(604)-1565.

Schwerdtfeger $W .$, and $U$. Radok, 1959:

Hodograph analysis as applied to the occurrence of clear-air turbulence. J. Meteorol $16: 588-592$.

Sekera, Z, , 1948 :

Helmholtz waves in a linear temperature field with vertical shear. J. Meteorol. 5:93-102.

Spillane, K.T., 1964:

A survey of the subtropical jet stream and clear air turbulence models. Report to be published: Dept. of Meteorol., University of Melbourne, Australia.

Webb, W.L., 1963:

Acoustic component of turbulence. J. App1. Meteor 2:286-291. 